\title{
Glycoprotein la C807T gene polymorphism and increased risk of recurrent acute coronary syndromes: a five year follow up
}

\author{
A M Leone, V De Stefano, F Burzotta, P Chiusolo, I Casorelli, K Paciaroni, E Rossi, A Sciahbasi, \\ L Testa, G Leone, F Crea, F Andreotti
}

D espite aggressive control of modifiable risk factors, recurrent acute coronary syndromes are still common, and the underlying mechanisms largely elusive. Glycoprotein $(\mathrm{Gp}$ ) Ia/IIa is one of several collagen receptors involved in platelet adhesion. ${ }^{1}$ A C807T gene variant of GpIa is related to $\mathrm{Gp} \mathrm{Ia/IIa} \mathrm{receptor} \mathrm{density} \mathrm{on} \mathrm{the} \mathrm{platelet} \mathrm{surface,}{ }^{2}$ with the density proportionate to the number of $\mathrm{T}$ alleles. ${ }^{2}$ Previous case-control studies in white subjects have associated this variant with acute ischaemic heart disease. ${ }^{3}$ As it is not known whether the 807T allele may also predict recurrent acute coronary syndromes, this was investigated in 117 survivors of a first acute coronary event; patients were followed for up to five years.

\section{METHODS}

Between 1996 and 1998 we enrolled 195 patients below the age of 65 years; these patients were discharged from our coronary care unit with a diagnosis of acute myocardial infarction (MI), according to World Health Organization criteria, (MI, $\mathrm{n}=141$ ) or severe Braunwald class IIIB unstable angina (UA, $\mathrm{n}=54$ ) at first presentation of disease. After informed consent for genetic analyses, a final number of 117 patients (79 MI, 38 UA) accepted follow up assessment which took place at six months, two years, and five years. Clinical evaluation was blinded to the results of genotyping. Major cardiovascular risk factors, angiographic extent of disease, and left ventricular ejection fraction (LVEF) were assessed at enrolment. Antiplatelet drugs during follow up consisted of aspirin or ticlopidine if aspirin was contraindicated. Following percutaneous coronary interventions, aspirin and ticlopidine were both prescribed for four weeks. Gp IIb/IIIa inhibitors were not administered.

The primary end point was the composite of fatal and nonfatal MI and UA, but additional separate analyses were carried out for incident MI or UA alone. During follow up, fatal MI was defined as death preceded by symptoms, or signs, indicative of prolonged myocardial ischaemia, while non-fatal MI and UA were defined as the index event by WHO criteria and as Braunwald class IIIB, respectively. Genotyping was completed in December 2001 by operators blinded to the clinical data, as previously described. ${ }^{3}$ KaplanMeier event-free survival curves were compared by log rank test. A Cox proportional hazard analysis was used to adjust for the effect of possible confounders on outcome. Discrete and continuous variables were analysed by Fisher's exact probability test and by Mann-Whitney U test. The concomitant prognostic values of cardiac troponins and $\mathrm{C}$ reactive protein were not assessed as their measurement was not well established when this study began. Considering the low estimated frequency of the TT genotype, and our previous data suggesting an increased risk of acute coronary syndromes for $\mathrm{T}$ allele carriers relative to CC homozygotes, ${ }^{3} \mathrm{CT}$ and TT genotypes were analysed as a single group. Assuming a frequency of CC, CT and TT genotypes of about $40 \%, 45 \%$ and $15 \%$, respectively, an average recurrence rate for the combined end point of about 15\%, 20\% and $40 \%$ at six months, one year, and five years, respectively, and a rough hazard ratio of 2 between $\mathrm{T}$ allele carriers and CC patients for the recurrence of the clinical end points, for an $\alpha<0.05$ and a power of $80 \%$, a sample of at least 115 patients would be needed.

\section{RESULTS}

Genotyping revealed 807CC in 49 patients (41.9\%), 807CT in 51 patients $(43.6 \%)$, and 807 TT in 17 patients (14.5\%). This distribution did not differ significantly from that found in the original population of 195 patients (CC $37.4 \%$, CT $47.7 \%$, TT $14.9 \%$ ). T allele carriers did not differ significantly from CC homozygotes for the major cardiovascular risk factors, extent of coronary disease, percentage undergoing surgical or percutaneous coronary revascularisation, antiplatelet drugs, and LVEF at baseline (table 1). There was also no significant difference in the use of $\beta$ blockers and angiotensin converting enzyme inhibitors between $\mathrm{T}$ allele carriers $(42 \%$ and $51 \%$, respectively) and CC homozygotes (45\% and 48\%, respectively). Mean follow up was 46 months with a maximum of five years. All 117 patients were assessed at 30 days; at this time three patients (all carriers of the $\mathrm{T}$ allele) had a recurrence; 115 patients $(98.3 \%)$ participated in follow up at six months, 86 patients $(73.5 \%)$ at two years, and 81 patients $(69.2 \%)$ at five years.

$\mathrm{T}$ allele carriers suffered significantly more events during follow up compared to patients homozygous for the $\mathrm{C}$ allele. The Kaplan-Meier survival curves free of MI and UA started to differ at two months $(p=0.034)$ and remained significantly different at six months, two years, and five years ( $\mathrm{p}=0.0009, \mathrm{p}=0.014$ and $\mathrm{p}=0.036$, respectively) (fig lA). The difference in event rates was still significant at six months, two years, and five years for incident MI $(\mathrm{p}=0.005, \mathrm{p}=0.075$ and $\mathrm{p}=0.048)($ fig $1 \mathrm{~B})$, but not for UA alone $(\mathrm{p}=0.07, \mathrm{p}=0.10$ and $\mathrm{p}=0.37$, power $73 \%$ ) (fig 1C). Comparing the three genotypes (CC $v$ CT $v$ TT), there was a trend towards a worse outcome with increasing number of $\mathrm{T}$ alleles $(\mathrm{p}=0.054, \log$ rank test). These results were confirmed in the subgroup of 79 patients who had an initial diagnosis of MI, in whom $\mathrm{T}$ allele carriers showed a worse outcome at five years for the composite end point $(\mathrm{p}=0.04)$ and for MI $(\mathrm{p}=0.04)$, but not for UA $(\mathrm{p}=0.48$, power $57 \%)$.

Abbreviations: Gp, glycoprotein; LVEF, left ventricular ejection fraction; $\mathrm{MI}$, myocardial infarction; UA, unstable angina 
Table 1 Clinical characteristics of the study population

\begin{tabular}{|c|c|c|c|c|}
\hline & All patients & T allele carriers & CC genotype & p Value* \\
\hline All & $117(100 \%)$ & $68(58.1 \%)$ & $49(41.9 \%)$ & \\
\hline Mean age (years) & $54.3(8.2)$ & $55.1(7.5)$ & $52.9(1.3)$ & 0.27 \\
\hline Females & $16(13.7 \%)$ & $10(14.7 \%)$ & $6(12.2 \%)$ & 0.79 \\
\hline Smokers & $71(60.7 \%)$ & $36(52.9 \%)$ & $35(71.4 \%)$ & 0.06 \\
\hline Systemic hypertension & $64(54.7 \%)$ & $37(54.4 \%)$ & $27(55.1 \%)$ & 1 \\
\hline Hypercholesterolemia & $52(44.4 \%)$ & $31(45.6 \%)$ & $21(42.9 \%)$ & 0.85 \\
\hline Family history of ischaemic heart disease & $44(37.6 \%)$ & $23(33.8 \%)$ & $21(42.9 \%)$ & 0.34 \\
\hline Diabetes mellitus & $19(16.2 \%)$ & $13(19.1 \%)$ & $6(12.2 \%)$ & 0.32 \\
\hline Mean left ventricular ejection fraction & $50.1 \%(10.2)$ & $49.4 \%(10.4)$ & $51.1 \%(9.9)$ & 0.42 \\
\hline Percutaneous coronary interventions & $30(25.6 \%)$ & $17(25.0 \%)$ & $13(26.5 \%)$ & 1 \\
\hline Coronary artery bypass grafting & $12(10.3 \%)$ & $8(11.8 \%)$ & $4(8.2 \%)$ & 0.76 \\
\hline Coronary angiography & $90(100 \%)$ & $54(79.4 \%)$ & $36(73.5 \%)$ & \\
\hline Single vessel disease & $34(37.8 \%)$ & $23(42.6 \%)$ & $11(30.6 \%)$ & 0.28 \\
\hline Multi vessel disease & $51(56.7 \%)$ & $29(53.7 \%)$ & $22(61.1 \%)$ & 0.82 \\
\hline
\end{tabular}

*p Values compare T allele carriers to CC genotype.

Hypercholesterolaemia was defined as: total cholesterol $>240 \mathrm{mg} / \mathrm{dl}$; diabetes as fasting glycaemia $>126 \mathrm{mg} / \mathrm{dl}$ on at least two occasions; hypertension as blood pressure $>140 / 90 \mathrm{~mm} \mathrm{Hg}$; smoking as a smoker of $>1$ cigarette per day at the time of admission; family history as documented acute coronary syndrome before 60 years of age in at least one first degree relative.

A

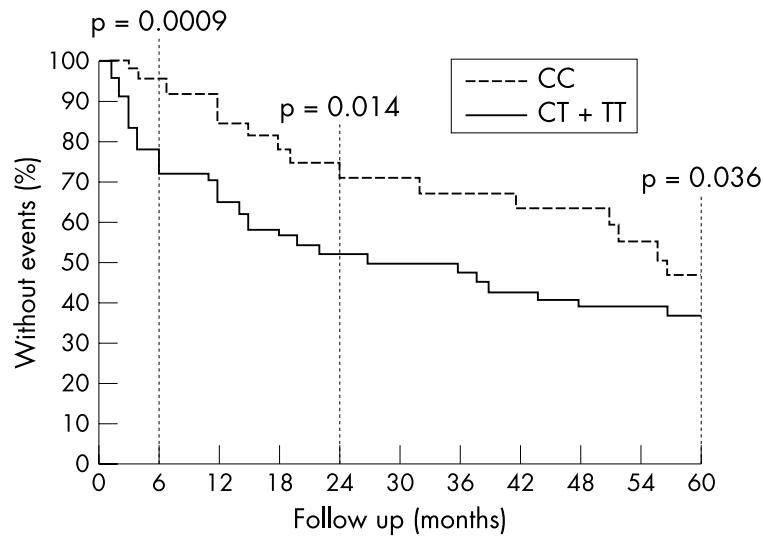

$\begin{array}{llllllllllll}\text { CC } & 49 & 47 & 49 & 24 & 21 & 21 & 18 & 17 & 17 & 14 & 11\end{array}$

$\begin{array}{llllllllllll}\mathrm{CT}+\mathrm{T} & 68 & 52 & 42 & 30 & 26 & 23 & 22 & 20 & 18 & 18 & 16\end{array}$

C

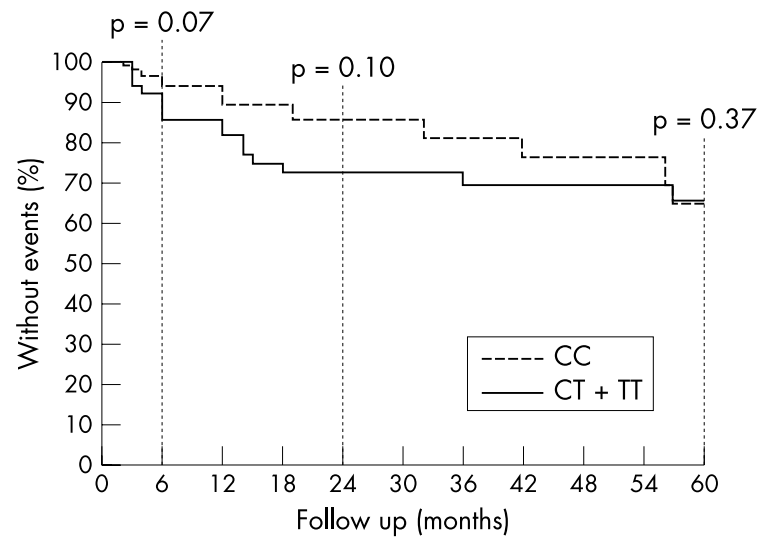

B

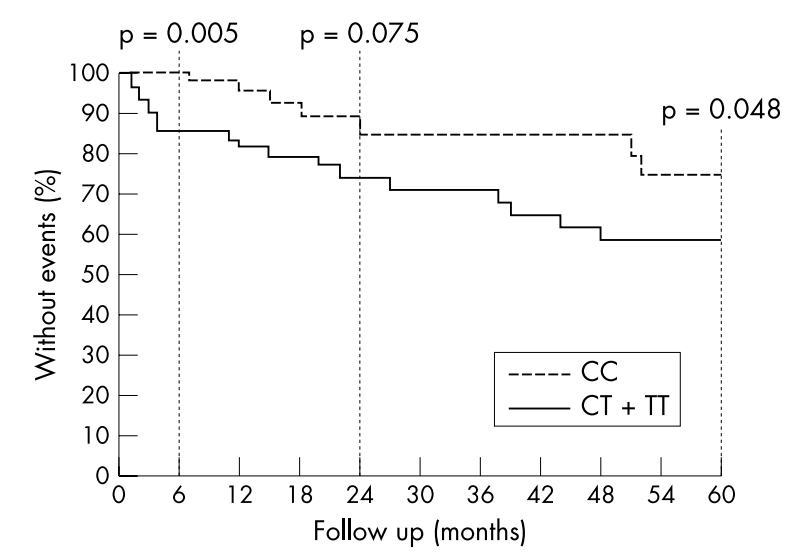

$\begin{array}{llllllllllll}\text { CC } & 49 & 49 & 41 & 26 & 21 & 21 & 21 & 21 & 21 & 15 & 13\end{array}$

$\begin{array}{llllllllllll}\mathrm{CT}+\mathrm{TT} & 68 & 57 & 44 & 39 & 28 & 24 & 24 & 22 & 20 & 20 & 18\end{array}$ $p=0.015$

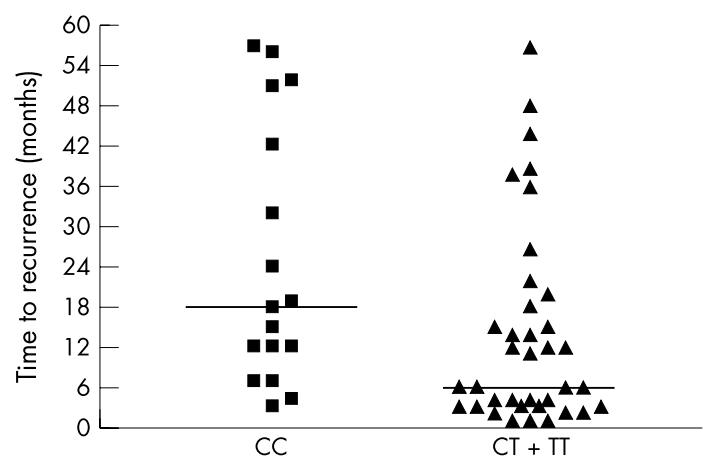

$\begin{array}{llllllllllll}\mathrm{CC} & 49 & 47 & 40 & 40 & 23 & 23 & 18 & 17 & 17 & 17 & 11\end{array}$

$\mathrm{CT}+\mathrm{TT} \quad 68 \quad 52 \quad 42 \quad 30 \quad 30 \quad 30 \quad 22 \quad 22 \quad 22 \quad 22 \quad 17$

Figure 1 Kaplan-Meier event-free survival curves ( $\mathrm{A}$ to $\mathrm{C}$ ) in T allele carriers (continuous curves) and in CC homozygotes (broken curves). Compared to CC homozygotes, significantly fewer T allele carriers were free of any event during the five year follow up and free of Ml at both six months and five years. Survival free of UA did not differ significantly between groups. Recurrences (D) occurred sooner in T allele carriers compared to CC

homozygotes (horizontal bars indicating median time to recurrence). 
In the entire group, after adjusting for age, sex, diabetes mellitus, LVEF $<40 \%$, type of index event, and use of revascularisation procedures, the relative risk for the primary composite end point among $\mathrm{T}$ allele carriers compared to non-carriers was 7.6 (95\% confidence interval (CI) 1.68 to $33.8, \mathrm{p}=0.007)$ at six months, 2.4 (95\% CI 1.19 to 4.83 , $\mathrm{p}=0.014)$ at two years, and $1.9(95 \%$ CI 1.05 to 3.43 , $\mathrm{p}=0.035)$ at five years. Median event-free survival was shorter in T allele carriers compared to CC homozygotes (27 v 57 months) and, among patients who experienced adverse events, these occurred sooner in the presence of the $\mathrm{T}$ allele (median $6 v 18$ months, $\mathrm{p}=0.015$ ) (fig 1D).

\section{DISCUSSION}

Our findings suggest that carriers of the 807T allele of the GpIa gene among patients suffering a first acute coronary syndrome before the age of 65 years may significantly increase the risk and anticipate the timing of a recurrent event over the next five years, even after correction for established prognostic factors. At six months, having the $\mathrm{T}$ allele increased the adjusted risk of recurrence by approximately sevenfold compared to homozygosity for the $\mathrm{C}$ allele. The less favourable outcome in T allele carriers appears to be attributable to a higher incidence of fatal and non-fatal MI rather than UA (although the power to detect differences in the rates of UA was below $80 \%$ ). The 807 T allele may thus confer susceptibility to more severe recurrences.

The 33.3\% recurrence rate of MI at five years seen in our cohort is comparable to that previously reported in survivors of acute coronary syndromes. ${ }^{4}$ Moshfeg and colleagues ${ }^{5}$ first described a threefold risk of MI among carriers of the 807TT genotype compared to $\mathrm{C}$ allele carriers. Several, though not all, subsequent cross sectional studies have confirmed the association between the C807T polymorphism and acute ischaemic heart disease. ${ }^{3}$ To our knowledge this is the first longitudinal study to investigate and identify a relation between a GpIa gene polymorphism and the risk of recurrences in patients presenting with acute coronary syndrome. Further studies are needed to confirm these preliminary findings and to assess whether the prognostic role of this polymorphism may be incremental over that of markers of myonecrosis and inflammation.

\section{Authors' affiliations}

A M Leone, V De Stefano, F Burzotta, P Chiusolo*, I Casorelli*, K Paciaroni*, E Rossi*, A Sciahbasi, L Testa, G Leone*, F Crea, F Andreotti, Institute of Cardiology and *Institute of Haematology, Catholic University, Rome, Italy

Correspondence to: Dr Antonio Maria Leone, Istituto di Cardiologia, Università Cattolica del Sacro Cuore, Largo A. Gemelli 8, 00168 Rome, Italy; antoniomarialeone@libero.it

Accepted 27 October 2003

\section{REFERENCES}

1 Nieuwenhuis HK, Akkerman JW, Houdii WP, et al. Human blood platelets showing no response to collagen fail to express surface glycoprotein la. Nature 1985;318:470-2.

2 Kunicki TJ, Kritzik M, Annis DS, et al. Hereditary variation in platelet integrin $\alpha 2 \beta 1$ density is associated with two silent polymorphisms in the $\alpha 2$ gene coding sequence. Blood 1997:89:1939-43.

3 Casorelli I, De Stefano V, Leone AM, et al. The C807T/G873A polymorphism in the platelet glycoprotein la gene and the risk of acute coronary syndrome in the Italian population. Br J Haematol 2001;114:150-4.
4 Stevenson R, Ranjadayalan K, Wilkinson $\mathrm{P}$, et al. Short and long term prognosis of acute myocardial infarction since introduction of thrombolysis. BMJ 1993;307:349-53

5 Moshfeg K, Wuillemin WA, Redondo M, et al. Association of two silent polymorphisms of platelet glycoprotein la/lla receptor with risk of myocardial infarction. A case-control study. Lancet 1999;353:351-4.

\section{WEB TOP 10}

www.heartjinl.com

These articles scored the most hits on Heart's website during February 2004

1 Nicorandil versus isosorbide dinitrate as adjunctive treatment to direct balloon angioplasty in acute myocardial infarction

N Ikeda, T Yasu, N Kubo, S Hashimoto, Y Tsuruya, M Fujii, M Kawakami, M Saito

February 2004;90:181-5. (Interventional Cardiology and Surgeryl

2 Indications for the closure of patent foramen ovale MJ Landzberg, $P$ Khairy

February 2004;90:219-24. (Education in Heart)

3 Clinical implications of the new definition of myocardial infarction

JK French, HD White

January 2004;90:99-106. (Education in Heart)

4 Diabetes and atherogenesis

M Fisher

March 2004;90:336-40. (Education in Heart)

5 Multi-vessel coronary disease and percutaneous coronary intervention

C Casey, DP Faxon

March 2004;90:341-6. (Education in Heart)

6 Recent insights into human coronary collateral development

M Fujita, $K$ Tambara

March 2004;90:246-50. (Review)

7 Acute pericardial disease: approach to the aetiologic diagnosis

$G$ Permanyer-Miralda

March 2004;90:252-4. (Mini-symposium)

8 Atrial fibrillation: an emerging epidemic? JS Steinberg

March 2004;90:239-40. (Editorial)

9 Cost of an emerging epidemic: an economic analysis of atrial fibrillation in the UK

S Stewart, N Murphy, A Walker, A McGuire, JJV McMurray March 2004;90:286-92. (Cardiovascular medicine)

10 Pericardial effusion: haemodynamic spectrum $R$ Shabetai March 2004;90:255-6. (Mini-symposium)

Visit the Heart website for hyperlinks to these articles, by clicking on "Top 10 papers"

www.heartjnl.com 